\title{
Transaction based indices for the UK commercial real estate market: an exploration using IPD transaction data
}

Article

Accepted Version

Devaney, S. and Martinez Diaz, R. (2011) Transaction based indices for the UK commercial real estate market: an exploration using IPD transaction data. Journal of Property Research, 28 (4). pp. 269-289. ISSN 1466-4453 doi: https://doi.org/10.1080/09599916.2011.601317 Available at https://centaur.reading.ac.uk/29410/

It is advisable to refer to the publisher's version if you intend to cite from the work. See Guidance on citing.

Published version at: http://www.tandfonline.com/doi/abs/10.1080/09599916.2011.601317

To link to this article DOI: http://dx.doi.org/10.1080/09599916.2011.601317

Publisher: Routledge

All outputs in CentAUR are protected by Intellectual Property Rights law, including copyright law. Copyright and IPR is retained by the creators or other copyright holders. Terms and conditions for use of this material are defined in the End User Agreement.

www.reading.ac.uk/centaur 
Central Archive at the University of Reading

Reading's research outputs online 


\title{
Transaction based indices for the UK commercial real estate market: an exploration using IPD transaction data
}

Steven Devaney (University of Aberdeen) and Roberto Martinez Diaz (Investment Property Databank)

\author{
Steven Devaney* \\ University of Aberdeen Business School \\ Edward Wright Building, Dunbar Street, \\ Aberdeen, AB24 3QY \\ United Kingdom
}

Roberto Martinez Diaz

Investment Property Databank

1 St. John's Lane,

London, EC1M 4BL

United Kingdom

* = corresponding author

This is an Accepted Manuscript of an article published by Taylor \& Francis in Journal of Property Research on 31/08/2011, available online:

http://www.tandfonline.com/10.1080/09599916.2011.601317

\section{Acknowledgements}

The authors thank lan Cullen and Malcolm Frodsham at IPD for their support and comments on this research. They would also like to thank David Geltner for his comments and for clarifications in respect of the MIT-CRE TBI series. The paper benefited from the constructive comments made by the anonymous referees and from feedback at the session of the 2010 European Real Estate Society conference where this work was first presented. The views expressed are not necessarily those of the organisations for whom the authors work and any mistakes or omissions are the responsibility of the authors alone. 


\title{
Transaction based indices for the UK commercial real estate market: an exploration using IPD transaction data
}

\begin{abstract}
The nature of private commercial real estate markets presents difficulties for monitoring market performance. Assets are heterogeneous and spatially dispersed, trading is infrequent and there is no central market place in which prices and cash flows of properties can be easily observed. Appraisal based indices represent one response to these issues. However, these have been criticised on a number of grounds; that they may understate volatility, lag turning points and be affected by client influence issues. Thus, this paper reports econometrically derived transaction based indices of the UK commercial real estate market using Investment Property Databank (IPD) data, comparing them with published appraisal based indices. The method is similar to that presented by Fisher et al. (2007) and used by MIT on NCREIF data, although it employs value rather than equal weighting. The results show stronger growth from the transaction based indices in the run up to the peak in the UK market in 2007. They also show that returns from these series are more volatile and less autocorrelated than their appraisal based counterparts, but, surprisingly, differences in turning points were not found. The conclusion then debates the applications and limitations these series have as measures of market performance.
\end{abstract}

\section{Keywords}

Transaction-based indices; Assessed value method; Appraisal smoothing; Sample selection effects; UK commercial real estate 


\section{Transaction based indices for the UK commercial real estate market: an exploration using IPD transaction data}

\section{Introduction}

Index construction in commercial real estate markets is not straightforward for a number of reasons. The heterogeneity of the assets concerned is one factor, as is the infrequent and irregular trading of these assets, meaning that prices are not observable for all properties in each period. Even in the case of those properties that do trade, the private nature of real estate transactions together with the lack of a central market in which transactions take place presents difficulties for obtaining the information necessary to produce robust measures of market performance. For these reasons, appraisal based rather than transaction based series predominate in terms of the measurement of investment returns from commercial real estate assets.

Appraisal based indices are possible owing to the obligations placed in many countries on certain groups of real estate investors to regularly revalue the assets they hold. Such revaluations are typically conducted under definitions whereby the figure produced should represent the price for which the property in question would sell. Hence, these appraisals can be used in construction of performance indices as proxies for prices in the absence of regular, repeated trading. However, an extensive academic literature has developed that highlights problems with appraisal based series. Some of these problems relate to the micro-level processes of appraisal itself, whilst others concern the aggregation of appraisal information into a market level series.

Micro-level issues revolve around the availability to appraisers of timely transaction evidence on prices and the subsequent selection and weighting of evidence during the 
appraisal process. These issues are discussed by Clayton et al. (2001), who review rational and behavioural explanations for why appraisers incorporate both current and past price information into the estimation of property values. In the context of limited and noisy price signals from recent trades, partial reliance on past evidence may be justifiable for producing an individual appraisal. When combining appraisals into an index, though, whilst random errors in individual assessments should cancel out, any systematic tendency across appraisals to rely partly on past evidence cannot be removed.

This suggests that appraisal based indices will provide a smoothed and lagged representation of underlying price movements in the real estate market. This is then problematic for analysis based on such series, as if volatility is understated and turning points are not captured, this affects risk-return comparisons and the measurement of relationships with other variables, such as return series for other assets. Furthermore, smoothing will be exacerbated if the index construction process allows the use of appraisals produced at different points in time to represent values as at a specific date. ${ }^{1}$ Meanwhile, a number of studies, reviewed by Crosby et al. (2010), have explored the potential for client influence on individual appraisals, which - if present - raises further concerns about the inputs being used.

Given these points, the creation of an alternative, transaction based series may seem desirable. However, overcoming the obstacles outlined at the start of the paper is difficult. In order to control for variations in the quality and timing of real estate transactions, several econometric procedures have been proposed. Yet gathering sufficient data for such methods at an adequate level of detail can be a problem and, without a sufficient quantity of data, transaction based indices may contain excessive amounts of estimation 'noise'. Another concern is whether those properties that trade are representative of the market in

\footnotetext{
${ }^{1}$ For instance, see Geltner \& Goetzmann (2000) for discussion of this problem in relation to the NCREIF index in the US.
} 
terms of their characteristics and price trends, either generally or during specific phases of the real estate cycle.

Thus, transaction based indices are not without problems and, for some applications, appraisal based series may be considered more reliable, such as in the area of investor benchmarking where regular, disaggregated reporting and comparison are required. Nonetheless, a transaction based series can potentially yield useful insights into the nature of commercial real estate markets and be an important aid to research, with the complementary functions of the two bases being advocated in Geltner \& Ling (2001). With this in mind, this paper presents transaction based indices generated from data on commercial real estate sales recorded in the Investment Property Databank (IPD) UK quarterly database. These are then compared with appraisal based series from the same source to see if new information about risk and market turning points is uncovered.

The structure of the remainder of the paper is as follows. In the next section, the method chosen for constructing transaction based indices is explained and justified. The third section then discusses the data available and sets out how the method was implemented from data preparation through to model estimation and the production of index values. The fourth section presents the results, which span the period Q1 2002 to Q2 2010. This was an interesting period to analyse given that it covered both the strong boom and subsequent collapse in the UK commercial real estate market, the latter occurring as the recent global financial crisis unfolded. The final section then concludes as to the applications and limitations of the series generated.

\section{Review of method}


The simplest forms of transaction based indices are those that compute an average of prices across all properties traded in each period. However, commercial real estate assets are heterogeneous and individual prices will reflect variations in quality between properties, whilst averages will reflect the attributes of the sample that traded in that interval. With low levels of trading, variations in average price over time may not only reflect market movements, but also fluctuations in the quality of assets sold. For this reason, hedonic regression has been advocated as a technique that explicitly models the effects of characteristics on product prices and so allows these effects to be controlled for in index construction. A hedonic regression typically takes the following form:

$$
\ln \mathrm{P}=\beta_{0}+\beta_{1} \mathrm{X}_{1}+\beta_{2} \mathrm{X}_{2} \ldots+\beta_{\mathrm{n}} \mathrm{X}_{\mathrm{n}}+\varepsilon
$$

$$
\begin{aligned}
& \text { Where } P=\quad \text { the sale price of a product } \\
& \mathrm{X}_{\mathrm{n}} \quad \text { represent } n \text { characteristics of that product } \\
& \beta_{n} \quad \text { are coefficients that capture the price impact of each characteristic } \\
& \varepsilon=\text { a random error term }
\end{aligned}
$$

Equation (1) may be applied on a period by period basis or estimated on pooled transaction data with time dummies as additional regressors. In either case, though, objections have been raised as to the difficulties of identifying all relevant price influences and the correct functional form (see Shiller, 1993: 129-131), as well as the problem of gaining adequate data on attributes from available data sources. If important factors are missing from the model above, this can lead to bias in the estimated coefficients unless the omitted factors happen to be orthogonal to the included variables. This, in turn, would bias estimates of index values from such a model.

In response to very limited data on land sales, Clapp (1990) proposed an alternative approach to hedonic regression for estimating real estate price indices. He noted that, 
whilst his data lacked information on characteristics, appraisals of different land parcels were available for the area he was studying. These were conducted periodically for the purposes of tax assessment. Clapp argued that these appraisals could be used in place of the attribute variables in equation (1). This is because, just as differences in attributes reflect variations in quality between assets, differences in assessed values made at a specific point in time also reflect such variations, as the appraiser takes physical and location characteristics of each property into account when forming a judgement about value.

Therefore, if a set of appraisals (denoted $A$ ) is available to substitute in place of characteristics in equation (1), the regression to be estimated would become:

$$
\ln \mathrm{P}=\beta_{0}+\beta_{1} \ln \mathrm{A}+\varepsilon
$$

Typically, the appraisals in equation (2) are observed for a specific base period and thus transactions should be screened for changes in characteristics between this point and the time of sale. As with a standard hedonic model, time dummies can be added or the model can be estimated on a period-by-period basis, especially if there are repeated sets of reference appraisals that can be utilised.

This approach does not have the extensive data requirements of the hedonic model and so is more easily applied as long as appraisal data is available for the market in question. Furthermore, assessed values may capture dimensions of quality that would be difficult to observe or measure within a hedonic framework (Fisher et al., 2003: 291). Yet an important issue concerns the ability of appraisals to effectively represent the price differences caused by variations in quality between properties. It is highly unlikely that differences between assets will be quantified perfectly and this has led to the relationship between assessed values and true market values being represented in the following way: 


$$
\ln \mathrm{A}=\gamma_{0}+\gamma_{1} \ln \mathrm{V}+\mu
$$

Where $A=\quad$ the assessed value
\[ \begin{array}{l}V=\quad \text { the true market value } \\ V_{0}, \nu_{1} \quad \text { capture potential systematic errors in assessment } \\ \mu \quad \text { is a random disturbance term that captures random error in assessment }\end{array} \]

This relationship has consequences for the use of assessed values in a property price model. The presence of errors means that the substitution of appraisals for hedonic variables is not as simple as suggested by equation (2). The observed appraisal is only a proxy for the true, but unobserved, value of the characteristics in each case. Thus, both it and the element of error in representing differences between properties are incorporated within the regression. Assuming no systematic errors for the moment, ${ }^{2}$ the actual model being estimated is:

$$
\ln \mathrm{P}=\beta_{0}+\beta_{1}(\ln \mathrm{A}-\mu)+\varepsilon
$$

With rearrangement, this yields:

$$
\ln \mathrm{P}=\beta_{0}+\beta_{1} \ln \mathrm{A}+\left(\varepsilon-\beta_{1} \mu\right)
$$

Hence, the independent variable in this regression model will be correlated with its error term, violating the assumptions under which OLS produces unbiased estimators. To resolve this issue, one approach is to use the instrumental variables technique. This involves finding another variable that is highly correlated with the problem variable, but has no relationship with the error component of that variable. Both the original variable and this instrument are then used in the estimation. This approach was followed by Clapp (1990), but subsequent studies that use the assessed value method have not tended to do

\footnotetext{
${ }^{2}$ In other words, assuming that $v_{0}$ in equation (3) is equal to 0 and $\gamma_{1}$ is equal to 1.
} 
this, relying instead on analysis in Clapp \& Giaccotto (1992) which suggests that the problem becomes negligible in large samples. ${ }^{3}$

Equation (3) also indicates that systematic errors in appraisal can influence model estimates. For instance, if there was a common lag across all appraisals, induced by microlevel processes, this will be captured by the $\beta$ coefficients. Yet this would not prevent quality differences between properties at a given time from being represented effectively. On the other hand, if appraisals are systematically inconsistent in cross-section, this would be problematic. Furthermore, the approach assumes that the attributes of each property and their relative pricing do not change between the appraisal date and the time of sale. Constancy of attribute pricing can also be an issue for hedonic models, but the presence in such cases of data on characteristics at least allows this assumption to be tested.

Despite these issues, the assessed value approach was adopted here owing to the presence in the IPD dataset of sets of repeat appraisals conducted at common time points. In every case, these were external appraisals of the Market Value of individual assets held in institutional investor portfolios. ${ }^{4}$ This enabled period by period estimation of models which mitigates some of the issues noted above. Meanwhile, although the IPD databases are optimised for the recording of cash flow data, they lack detailed information on building quality and characteristics, which makes it difficult to apply the hedonic method, though certain key attributes (such as property type, address and floorspace) are recorded.

\footnotetext{
${ }^{3}$ Nonetheless, at an early stage of the research, a comparison of results from OLS and instrumental variables estimations was performed. The indices generated by each were virtually identical, suggesting that the instrumental variables approach was unnecessary. Further details of this comparison can be obtained from the authors on request.

${ }^{4}$ Market Value is defined by the IVSC as "The estimated amount for which a property should exchange on the date of valuation between a willing buyer and a willing seller in an arm's-length transaction after proper marketing wherein the parties had each acted knowledgeably, prudently and without compulsion" (RICS, 2010).
} 
Another issue common to all transaction based index methods is that of sample selection. This concerns the interrelationship between characteristics and the behaviour of market participants in bidding for and accepting bids on properties, which then affects both the sample of buildings that sell and the prices that are observed. As Gatzlaff \& Haurin (1998) explain, sales only occur when the offer price for a property exceeds the reservation price of the seller. Furthermore, the reservation prices of buyers and sellers (which are unobserved) may be influenced by particular characteristics and external conditions, which, in turn, alter the likelihood of different assets trading and the prices that will be realised, with those assets that do sell potentially providing a distorted picture of general market movements.

Gatzlaff \& Haurin (1998) therefore propose the use of a procedure developed by Heckman (1979) that both tests and corrects for the existence of any bias caused by selection effects. ${ }^{5}$ This is with the insight that, although the differences in reservation prices are unobserved in each case, the outcome in terms of whether or not a property sold can be observed. This outcome then may be modelled as a function of observable factors using probit modelling techniques, which estimate the effects of the different factors on the likelihood of an event (sale) occurring, as well as the overall likelihood of sale for the observation in question. Defining the dependent variable in such a model as:

$$
S= \begin{cases}1, & \text { if } \mathrm{RP}^{\mathrm{b}} \geq \mathrm{RP}^{\mathrm{s}} \\ 0, & \text { otherwise }\end{cases}
$$

With RP denoting the reservation price of either a buyer (b) or a seller (s), the following can be estimated:

$$
\operatorname{Pr}[\mathrm{S}=1]=\Phi\left[\omega_{1} \ln \mathrm{A}+\sum \gamma_{\mathrm{n}} \mathrm{X}_{\mathrm{n}}\right]+\eta
$$

\footnotetext{
${ }^{5}$ See also Fisher et al. (2003) for a detailed exposition.
} 
Where $A=$ the assessed value of the property

$X_{n} \quad$ represent $n$ further factors hypothesised to be influential on sale decisions

$\omega, \gamma \quad$ estimate the impact on sale probability of individual variables

(1) is the cumulative density function for the standard normal distribution, and

$\eta \quad$ is an estimation error term

A key output from equation (7) is a parameter termed the inverse Mills ratio. For all assets, this estimates the amount of error that would be predicted by an uncorrected regression of prices on to appraisals had that property been observed in the sample of sales. The values of this parameter for the sold properties can then be entered as an additional regressor in equation (2) to counteract the bias in the errors of that model that would arise from sample selection effects. Thus, the new price model to be estimated is:

$$
\ln \mathrm{P}=\beta_{0}+\beta_{1} \ln \mathrm{A}+\sigma_{\varepsilon \eta} \lambda+v
$$

Where $\lambda=$ the inverse Mills ratio as calculated for each observation

$\sigma_{\varepsilon \eta} \quad$ is a coefficient that estimates the covariance in errors between equations

(2) and (7)

$v=\quad$ the new unbiased error term

The significance of the coefficient on $\lambda$ is then conventionally treated as a test of whether sample selection bias is present in the data being researched.

The two-step procedure outlined above was adopted by Fisher et al. (2003) in their research on sales recorded in the NCREIF database for the US real estate market, though with some differences in the actual models estimated. For instance, their proxy for missing hedonic information was the log of the property purchase price and both this and the dependent variable were divided by the size of the asset in square feet. They also used time, property type and location dummies in their models. Their findings suggest that the 
selection correction procedure has an important impact on index results, as illustrated by a comparison with an uncorrected price series.

In contrast, later research by Fisher et al. (2007) found that, whilst the first stage model worked well as a model of sale probability, the impact of selection bias on the estimated price series was not significant. In this study, capital value per square foot was adopted as the composite hedonic variable, whilst type, location and time dummies were once again used to augment the estimations. An interesting aspect of their specification is that, unlike in earlier papers, the appraisals do not refer to a fixed date, but lie at a fixed distance in time from the transaction ( 2 quarters before). In addition, both this and the study by Fisher et al. (2003) extract further information from the probit model to present liquidity corrected price series. ${ }^{6}$

This study takes a broadly similar approach to Fisher et al. (2007). However, it presents both OLS and selection corrected indices and, rather than pooling transaction data, models are estimated for each and every quarter. This enables variations in sample selectivity to be studied and prevents the minor historical restatements associated with pooled models should these series be updated. On the other hand, it does entail some loss in statistical efficiency, as well as being relatively cumbersome to implement. Meanwhile, actual and not per square foot versions of appraisals and prices are used (of which logs are then taken), and value weighted instead of equal weighted series are constructed, enabling comparison with published appraisal based indices for the UK. Value weighting is achieved by applying the model coefficients to unsold assets in a mass appraisal process, described in the next section. Finally, the paper concentrates solely on variable liquidity transaction based series.

\footnotetext{
${ }^{6}$ The research by Fisher et al. (2007) underlies the transaction based series for the US real estate market now published regularly by the MIT Centre for Real Estate in collaboration with NCREIF. See http://web.mit.edu/cre/research/credl/tbi.html (link correct as at March 2011).
} 


\section{Data and implementation}

The data used in this study are drawn from the IPD UK quarterly database. IPD are now well known for their provision of performance benchmarking services and appraisal based indices in many major real estate markets. In the UK, the quarterly database and its associated index are a relatively recent development, with the majority of data dating back only to the end of $2000 .^{7}$ By the end of June 2010 , though, 8,416 properties worth around f98bn were included in the quarterly index (IPD, 2010a), with this database forming a large subset (approximately 80\%) of the older annual database and index, the latter documenting UK real estate investment returns back to 1970 .

As noted earlier, this database is rich in terms of cash flow data, but has less information on asset characteristics. However, some information on characteristics was utilised to form either filters for defining the assets to be analysed or as variables for the models themselves. Meanwhile, the use of a procedure to test and correct for sample selection bias meant that data on all assets, whether held or sold, had to be extracted and analysed. The total number of properties available in each quarter is disclosed in Table 1 together with counts of the number of sales that were used in the price models. The modelling focuses on sales rather than purchases and is conducted over Q1 2002 to Q2 2010.

INSERT TABLE 1 ABOUT HERE

\footnotetext{
${ }^{7}$ There is, however, a long established monthly database and index for the UK that comprises mostly unitised funds and which stretches back to December 1986.
} 
The filters applied to the data were as follows. First, the analysis concentrates on the three main types of commercial real estate in UK investor portfolios; retail, office and industrial. These sectors account for $95 \%$ of the assets in the quarterly database. Second, to exclude 'flips' (properties sold within a very short time of being bought), only properties held for at least one year were included in the exercise. ${ }^{8}$ Third, properties were excluded if they had data missing from a field required by the models, excepting sale price, which will be unobserved for those properties that have not yet been sold. Finally, anomalous cases were excluded by dropping assets whose value or sale price was less than $£ 10,000$, greater than $f 1.5 \mathrm{bn}$, or sales where the mark up on previous appraisal lay outside the range $-50 \%$ to $+100 \%$, so that these did not distort estimations.

More information about the pattern of sales is given in Figure 1. This graphs the number of sales in each quarter alongside quarterly capital growth as recorded by the IPD All Property appraisal based index. The graph shows there was more selling at the beginning and towards the end of the time frame in question. Perhaps surprisingly, this tends to correspond with weak rather than strong market conditions, with some of the quarters exhibiting most sales occurring during the muted real estate market of 2002 and the falling market of 2008 (note that purchases by institutional investors did decline markedly in the latter case). There were typically more sales of retail properties than of the other two property types, but this reflects the relative size of each sector in the dataset as a whole.

INSERT FIGURE 1 ABOUT HERE

\footnotetext{
${ }^{8}$ It is well documented that such 'flips' can have a distorting effect on price indices, particularly when using the repeat sales method, e.g. see Clapp \& Giaccotto (1999).
} 
Only sold properties were used to estimate the price models shown in equations (2) and (8), the former equation being used for the OLS procedure. However, both sold and held properties were required for the first stage of the Heckman procedure, as set out in equation (7). The actual models estimated are shown at the foot of Table 2 and this table also provides definitions of each of the variables used.

\section{INSERT TABLE 2 ABOUT HERE}

Both of the price models incorporate additional 0/1 dummies and these are used to distinguish separate segment price trends. The segment dummies were defined in such a way as to strike a balance between disaggregation of the most important parts of the market and representation, such that sales in each category were observed in every period. Even then, there were no Shopping Centre sales during Q2 2009, which meant that the non-traded assets had to be treated as Standard Retail properties during the mass appraisal stage for that quarter. Meanwhile, fund dummies in the selection model identify various types of owner that may be more or less active in selling properties at different points in time. This, in turn, could influence the composition of the sale samples.

Other available variables thought to be important in affecting sale decisions, and so used in the selection model, were recent performance (measured by ANNTR), the yield of the asset in question (EYLD) and the length of time that each property had been in the portfolio (HOLDING). Both (sector) returns and elapsed time since purchase were found to influence propensity to trade in a previous study of the UK market by Collett et al. (2003), whilst a returns variable was employed successfully by Fisher et al. (2004) in their sale probability study. The dataset does not record whether assets are leveraged, whilst the 
appraisal is used to account for factors such as size and age in both stages of the modelling process. ${ }^{9}$

As in Fisher et al. (2007), the appraisal used for the $L N C V$ variable is not that recorded for the quarter prior to sale, but is instead the one from the quarter before. This is to ensure that this variable is independent of the sale price variable. For instance, if an appraiser is aware that a sale is being negotiated, the amount under discussion may influence the appraisal that is then produced for that asset. Empirical evidence on movements in appraisals prior to month of sale has been presented by Crosby et al. (2003) that would seem to support this contention. Subsequently, their findings led to the use of a similar screening process within UK industry studies of appraisal accuracy (e.g. RICS, 2009).

The use of an appraisal from two quarters before sale rather than from the preceding quarter does have an influence on results. Tests using the set of appraisals from one quarter beforehand generated indices that tracked the appraisal based series much more closely than those reported in the following section. Although this could reflect greater accuracy in relation to market conditions or changes to the asset before sale, it is also consistent with appraisers gaining knowledge of negotiated price. Thus, an apparently small difference between prices and appraisals made under these circumstances would be used to predict prices for non-traded assets whose appraisals were not similarly informed. For this reason, the two quarter assumption was retained.

Both the OLS and Heckman procedures were then applied to the data for each quarter. Once the models had been estimated, the coefficients from each price regression were extracted so that they could be used in a mass appraisal process. This process was conducted as follows. In a given quarter, all assets that did not trade during that quarter

\footnotetext{
${ }^{9}$ The first stage regression is not intended to be a detailed model of the property sale decision in its own right. Fisher et al. (2004) consider this decision in a separate paper from their own index research.
} 
were identified. The coefficients from the sale price regression for the previous quarter were then used to predict a start (In) price for this sample. Next, coefficients from the sale price regression for the current quarter were used to predict an end (In) price for these assets. The predicted log prices were then exponentiated, but as this provides biased predictions of cash prices, these values were adjusted in the following manner (see Miller, 1984):

$$
\hat{\mathrm{P}}=\exp (\ln \hat{\mathrm{P}}) \times \exp \left(\hat{\sigma}^{2} / 2\right)
$$

Here, $\sigma^{2}$ is the Mean Squared Error of the regression that generated the predicted In price.

The estimated start prices and end prices were then separately summed either for all assets or for a subset of particular interest. The change between these two totals in each quarter was then computed. This percentage change represents a value weighted capital return figure that is derived from transaction evidence on conditions in the real estate market. These rates of change can then be chain-linked into a longer series, within which the samples are held constant over individual computation intervals, but across which new assets are allowed to enter as the composition of the real estate market changes. The results of the regressions and the computed indices are presented next.

\section{Results}

The first results produced for each quarter were those from estimation of equation (7), the first stage probit model in the Heckman procedure. As noted in section 2, this examines factors affecting the likelihood of sale. These results can be summarised as follows. ${ }^{10}$ The variable most often significant at the $5 \%$ level was $L N C V$ (in 24 out of 34 quarters). This almost always had a negative coefficient, which suggests that larger, more valuable

\footnotetext{
${ }^{10}$ Regression output from the quarterly probit models can be obtained from the authors on request.
} 
properties had a lower probability of sale, something also found by Collett et al. (2003) for the period 1981-1998. In contrast, the other continuous variables in the model, ANNTR, EYLD and HOLDING, were not typically significant and exhibited no strong patterns, despite prior expectations that these variables would be important.

Meanwhile, with regard to the dummy variables, those denoting types of owner were significant more often than the segment dummies and provide a clearer story. Through the first half of the time frame, there were significant and negative coefficients on either most or all of the included fund dummies, suggesting that properties were more likely to be sold if they were in the portfolios of owners in the omitted category, life insurance funds. This then changed during the downturn in the market from mid-2007 onwards, whereby both significant and positive coefficients were consistently found on the dummy for unitised funds as these became sellers in order to meet unit redemptions. However, whilst these findings suggest that selling patterns are not entirely random, it is not clear from this model alone whether they could distort a price index as a result.

The second set of results relates to the uncorrected OLS and selection corrected price models. The coefficients from the estimations and their significance levels in each case are indicated in Tables 3 and 4. The coefficients on $L N C V$ capture the relationships between prices and appraisals from two quarters beforehand. Owing to the time difference, it does not provide a measure of appraisal accuracy. Instead, the coefficient incorporates the effect of both the distance in time between these figures and any general inertia present in the appraisals. When computing quarterly price changes, it is then shifts in this relationship between sets of transactions that drive the changes observed. The segment dummies test whether different parts of the market exhibit distinct price relationships. 
INSERT TABLE 3 ABOUT HERE

INSERT TABLE 4 ABOUT HERE

The final column of Table 4 records the coefficients on the INVMILLS variable for the selection corrected model. The significance of this variable is one test of whether sample selection bias was an influential factor in that quarter, thus justifying the adoption of a procedure to correct for this bias. As can be seen from the table, selection bias appears to be an issue in 22 of the 34 quarters examined. Furthermore, there are two distinct phases where a persistent effect is in evidence. These are from Q2 2004 to Q2 2005 inclusive and from Q2 2007 until the end of the time frame researched. The latter interval, spanning over three years, suggests that sample selectivity may be more important as a phenomenon during downturns in the real estate market.

The results from the mass appraisal procedure, using the coefficients from the price models, are displayed in Figures 2 and 3. These show the estimated price indices and their period-to-period changes, respectively, at the all property level of aggregation. For comparison, the charts also include the All Property appraisal based series published in the IPD UK Quarterly Digest (IPD, 2010b). ${ }^{11}$ It is clear from Figures 2 and 3 that there are broad similarities between the three series, but the two transactions based indices rise further and are more volatile than the appraisal index. However, movements in the transaction series do not appear to lead those in the appraisal based series over this period.

\footnotetext{
${ }^{11}$ This does mean that there are some differences in the underlying samples as well as in terms of the basis being compared (transaction vs. appraisal). However, comparisons with appraisal based indices derived from the filtered sample provide qualitatively similar findings to those discussed here.
} 


\section{INSERT FIGURE 2 ABOUT HERE}

\section{INSERT FIGURE 3 ABOUT HERE}

Table 5 extends the comparison further by providing summary statistics on each of the series concerned. Panel A contains information on the IPD series at both the all property and three sector levels, whilst panels $B$ and $C$ contain similar information for the transaction indices. The similarity in the turning points shown by these different series is striking and is returned to below. Aside from this, larger rises in the transaction series are again apparent, whilst the selection corrected indices also exhibit stronger falls. ${ }^{12}$ Meanwhile, the volatility of each transaction based series is always higher than that of its appraisal based counterpart, whilst the autocorrelation coefficients are lower in each case. Nonetheless, for the selection corrected indices, the coefficients are all still some way above zero, though only just above the value of 0.25 that has been shown to be possible from the averaging of underlying data that follows a random walk (Brown \& Matysiak, 2000).

\section{INSERT TABLE 5 ABOUT HERE}

The extent to which transaction series are more volatile is of interest given an earlier literature that tries to estimate the 'true' volatility of commercial real estate markets through econometric manipulation of appraisal indices. Several methods of desmoothing

\footnotetext{
${ }^{12}$ The industrial series produced by the selection corrected model is anomalous in showing a smaller rise than its appraisal based counterpart, but otherwise its behaviour is consistent with the general discussion.
} 
appraisal based series have been proposed, some which are reviewed by Geltner et al. (2003). Their article reports the ratios by which standard deviations have been found to increase when such procedures are implemented. Typically, the standard deviations are 1.5 to 5 times greater than those measured from raw appraisal based data, dependent on the method, period and frequency of data being examined. Here, the standard deviations of the transaction based all property series are 1.4 times higher than that of the appraisal based series, whilst, for the sector series, it is between 1.4 and 1.8 times higher. These multiples lie at the lower end of the range noted above, but are arguably more consistent with later studies that do not impose assumptions of market efficiency and zero autocorrelation in returns when desmoothing real estate data. ${ }^{13}$

The most surprising result indicated by Table 5 is that of the similarity in turning points between the two types of series. It was anticipated that movements in the transaction based indices would lead those in the appraisal based ones, but this was not so in terms of marking the top of the cycle (c. Q2 2007) and not consistently so in relation to the market trough (c. Q2 2009). Admittedly, the OLS based retail series does peak in Q2 2006, but it does not start to consistently fall until Q3 2007. In general, the profile of the main OLS series is rather erratic through the downturn, with occasional spikes upwards, and this unusual behaviour coincides with the run of quarters where the Heckman procedure indicates sample selection bias.

In contrast, the selection corrected index for all property appears to have a more plausible profile from the peak of the market onwards and indicates an earlier date for the bottom of the market (Q1 2009) than the appraisal index, although this is primarily driven by movements in the retail sector. For the office and industrial sectors, the transaction series generally lag rather than lead their appraisal based counterparts. Meanwhile, as an

\footnotetext{
${ }^{13}$ See also Wang (2006), whose alternative methodology proposes a ratio for volatility of 1.5 to 1.9 times that found in UK appraisal based series.
} 
additional comparator, the last row of Table 5 shows that the indirect (public) real estate market peaked much earlier than the direct (private) market measures presented here. The comparison is complicated by a break in the real estate equities index occasioned by the conversion of many large listed UK property companies to REIT status from January $2007 .{ }^{14}$ Nonetheless, it does place the magnitude and volatility of changes in the transaction series into some perspective. Disappointingly, these series are no more correlated with the indirect market than the appraisal based measures.

The findings with regard to turning points are likely to reflect several factors. First, sales occur at different times within each quarter, but the index construction method treats all evidence for that quarter equally in the estimation process. Thus, there is some temporal aggregation in the procedures adopted, although this does have the advantage of reducing the amount of noise in the series, which would potentially dominate a higher frequency estimation given the small samples of sales available. Furthermore, this should only introduce a small lag in the transaction series relative to the underlying market and does not in itself explain the similarity in turning points with the appraisal indices.

Second, the date recorded in the dataset for each sale is the final (legal) completion date, but prices are typically agreed between buyer and seller before this point. For instance, figures in Crosby \& McAllister (2004) indicate a median time of 62 days between price agreement and exchange of contracts and 19 days from exchange to completion for sales of UK institutional grade properties. This would imply that, in many cases, a price applies to a negotiation concluded two or three months before formal completion. Yet the same authors also note substantial variation in timings between individual sales together with the possibility of price being renegotiated in the due diligence phase of the transaction

\footnotetext{
${ }^{14}$ The series summarised by Table 5 is a composite of the FTSE All Share Real Estate sector index until the end of 2006 and the FTSE All Share REIT index from Q1 2007 onwards. The indices are of price changes to be consistent with the other data.
} 
process. This suggests that some prices reflecting market conditions in an earlier quarter are being analysed in a later one, but no systematic adjustment can be made to sale dates to mitigate this. Thus, the collection of data on agreed price and date of sale agreement would enable more responsive series to be constructed.

However, it should be noted that this issue is not unique to this study. Both Gatzlaff \& Geltner (1998: 20) and Fisher et al. (2007: 24) report that they were restricted to using completion dates in their research. Nonetheless, these studies of US markets still found that transaction based series led NCREIF appraisal based counterparts. Therefore, a third factor may be that the IPD appraisal based indices do not lag the underlying UK market to the extent that appraisal series do in the US, ${ }^{15}$ with each appraisal used in the UK series being based on a genuine external reappraisal of the asset for the quarter in question. In contrast, the NCREIF series for the US have historically used a mix of old ('stale') and new appraisals to generate index values; thus, the benefit of a transaction index here as a faster indicator of the market appears to be much greater.

Finally, tests were conducted to establish whether the distributions of transaction based returns differ from those produced by appraisal series. Previous research on appraisal based returns, both in time series and cross-section, have found them to be non-normal and leptokurtic (peaked and with fat tails). ${ }^{16}$ If this accurately characterises the nature of returns in the underlying real estate market, this has important implications for portfolio construction and asset allocation. Table 6 reports the skewness and kurtosis of each series considered so far, as well as results for the Jarque-Bera test of normality.

\footnotetext{
${ }^{15}$ Similar conclusions were reached in the comparative study of UK and US indices by Barkham \& Geltner (1995), although the UK appraisal index in this case was the JLW index. They also suggest that the greater relative homogeneity of the UK real estate market may be a further positive influence on the ability of the appraisal indices to reflect market movements.

${ }^{16}$ See Lizieri \& Ward (2000) and Young et al. (2006) for evidence and reviews of the literature.
} 


\section{INSERT TABLE 6 ABOUT HERE}

The results in Table 6 for the appraisal series are consistent with earlier studies in rejecting normality and finding skewness and leptokurtosis. However, for two of the four OLS series and for all of the selection corrected transaction series, normality in the time series returns cannot be rejected at conventional significance levels, whilst excess kurtosis all but disappears. This is a very interesting finding, but more research is needed to be certain that this typifies underlying market returns and is not simply a product of estimation noise or the specific time period being studied in this case.

\section{Conclusions}

This study has produced transaction based indices using IPD data on commercial real estate sales in the UK. Its aim was to establish whether these could provide new information about risk and turning points in this market, especially in relation to existing information provided by established appraisal based series. The study uses the 'assessed value' method first proposed by Clapp (1990) and recently adapted and applied to data on sales of US investment grade real estate by Fisher et al. (2007). It tests similar procedures to the latter study in respect of correcting for sample selection effects, but, in contrast to that research, uses output from the modelling to produce value weighted indices that are then compared with similarly weighted appraisal indices for the UK real estate market.

The results provide new evidence on the utility of transaction based indices for commercial real estate markets outside of the US, where, to date, most debate on this topic has taken place. The series exhibited expected increases in volatility and in the magnitude of rises and falls in price levels relative to appraisal based comparators for the 
period Q1 2002 to Q2 2010. However, the transaction based indices were no faster in marking important turning points in this market and this appears to arise from a combination of issues, including data issues that generate some lags in the transaction series. This raises questions about their utility as barometers of the market, but, on the other hand, the series could be of much use in research owing to the estimates that they provide of the volatility of the commercial real estate market at an aggregate level.

In addition, these estimates could be used to inform applications such as risk modelling and asset allocation, providing an alternative perspective to the results of desmoothing studies conducted on UK real estate data. It is also possible that transaction based series constructed in this manner could assist in market analysis with regard to the extent to which prices are rising or falling, potentially helping in the identification of price bubbles. However, for applications that require precision and continuity at disaggregated levels, such as performance benchmarking, these series would not be appropriate. In fact, from this dataset, credible series could not be produced below the level of the three main sectors of the UK commercial real estate market. ${ }^{17}$ Therefore, the series could only be complements and not competitors to the appraisal based indices that are currently produced.

\section{Acknowledgements}

The authors thank lan Cullen and Malcolm Frodsham at IPD for their support and comments on this research. They would also like to thank David Geltner for his comments and for clarifications in respect of the MIT-CRE TBI series. The paper benefited from the constructive comments made by the anonymous referees and from feedback at the session

\footnotetext{
${ }^{17}$ Recall that there were also no sales in the Shopping Centre segment in one of the quarters, but by value this segment represents a large fraction of the UK real estate investment universe.
} 
of the 2010 European Real Estate Society conference where this work was first presented. The views expressed are not necessarily those of the organisations for whom the authors work and any mistakes or omissions are the responsibility of the authors alone.

\section{Notes on contributors}

Dr Steven Devaney is a Lecturer in Real Estate at the University of Aberdeen Business School. His teaching and research are focused on commercial real estate investment. Previously, he has worked for Investment Property Databank and at the University of Reading.

Roberto Martinez Diaz now works in the Real Estate Strategy and Research team at Aviva Investors. Whilst the paper was being written, he was Senior Quantitative Analyst in the research department of Investment Property Databank.

\section{References}

Barkham, R. and Geltner, D. (1995), 'Price Discovery in American and British Property Markets', Real Estate Economics, 23 (1): 21-44.

Brown, G. R. \& Matysiak, G. A. (2000), 'Sticky Valuations, Aggregation Effects, and Property Indices', Journal of Real Estate Finance and Economics, 20 (1): 49-66.

Clapp, J. M. (1990), 'A methodology for constructing vacant land price indices', Journal of the American Real Estate and Urban Economics Association, 18 (3): 274-293. 
Clapp, J. M. and Giaccotto, C. (1992), 'Estimating Price Indices for Residential Property: A Comparison of Repeat Sales and Assessed Value Methods', Journal of the American Statistical Association, 87 (418): 300-306.

Clapp, J. M. and Giaccotto, C. (1999), 'Revisions in Repeat-Sales Price Indexes: Here Today, Gone Tomorrow?', Real Estate Economics, 27 (1): 79-104.

Clayton, J., Geltner, D. and Hamilton, S. W. (2001), 'Smoothing in Commercial Property Valuations: Evidence from Individual Appraisals', Real Estate Economics, 29 (3): 337360.

Collett, D., Lizieri, C. and Ward, C. (2003), 'Timing and the Holding Periods of Institutional Real Estate', Real Estate Economics, 31 (2): 205-222.

Crosby, N., Devaney, S., Key, T. and Matysiak, G. (2003), Valuation Accuracy: Reconciling the Timing of the Valuation and Sale, Working Papers in Real Estate \& Planning 06/03, University of Reading.

Crosby, N., Lizieri, C. and McAllister, P. (2010), 'Means, Motive and Opportunity? Disentangling Client Influence on Performance Measurement Appraisals', Journal of Property Research, 27 (2): 181-201.

Crosby, N. and McAllister, P. (2004), 'Deconstructing the Transaction Process: An Analysis of Fund Transaction Data', Working Paper Two, Liquidity in Commercial Property Markets, Investment Property Forum.

Fisher, J., Gatzlaff, D., Geltner, D. and Haurin, D. (2003), 'Controlling for the Impact of Variable Liquidity in Commercial Real Estate Price Indices', Real Estate Economics, 31 (2): 269-303. 
Fisher, J., Gatzlaff, D., Geltner, D. and Haurin, D. (2004), 'An Analysis of the Determinants of Transaction Frequency of Institutional Commercial Real Estate Investment Property', Real Estate Economics, 32 (2): 239-264.

Fisher, J., Geltner, D. and Pollakowski, H. (2007), 'A Quarterly Transactions-based Index of Institutional Real Estate Investment Performance and Movements in Supply and Demand', Journal of Real Estate Finance and Economics, 34 (1): 5-33.

Gatzlaff, D. and Geltner, D. (1998), 'A Transaction-Based Index of Commercial Property and its Comparison to the NCREIF Index', Real Estate Finance, 15 (1): 7-22.

Gatzlaff, D. H. and Haurin, D. R. (1998), 'Sample Selection and Biases in Local House Value Indices', Journal of Urban Economics, 43 (2): 199-222.

Geltner, D. and Goetzmann, W. (2000), 'Two Decades of Commercial Property Returns: A Repeated-Measures Regression-Based Version of the NCREIF Index', Journal of Real Estate Finance and Economics, 21 (1): 5-21.

Geltner, D. and Ling, D. (2001), 'Ideal Research and Benchmark Indexes in Private Real Estate: Some Conclusions from the RERI/PREA Technical Report', Real Estate Finance, $17(4): 17-28$.

Geltner, D., MacGregor, B. D. and Schwann, G. M. (2003), 'Appraisal Smoothing and Price Discovery in Real Estate Markets', Urban Studies, 40 (5/6): 1047-1064.

Heckman, J. J. (1979), 'Sample Selection Bias as a Specification Error', Econometrica, 47 (1): $153-161$.

IPD (2010a), IPD UK Quarterly Property Index: Results for the quarter to 30th June 2010, Investment Property Databank, London.

IPD (2010b), IPD Quarterly Digest Q1 2010, Investment Property Databank, London. 
Lizieri, C. and Ward, C. (2000), 'The distribution of commercial real estate returns' in J. Knight and S. Satchell (Eds), Return Distributions in Finance, Butterworth-Heinemann, Oxford, pp. 47-74.

Miller, D. M. (1984), 'Reducing Transformation Bias in Curve Fitting', The American Statistician, 38 (2): 124-126.

RICS (2009), Valuation and Sale Price Report 2009, Royal Institution of Chartered Surveyors, London.

RICS (2010), RICS Valuation Standards, $6^{\text {th }}$ edition, Royal Institution of Chartered Surveyors, London.

Shiller, R. J. (1993), Macro Markets: Creating Institutions for Managing Society's Largest Economic Risks, Clarendon Lectures in Economics, Oxford University Press, Oxford.

Wang, P. (2006), 'Errors in Variables, Links between Variables and Recovery of Volatility Information in Appraisal-Based Real Estate Return Indexes', Real Estate Economics, 34 (4): 497-518.

Young, M. S., Lee, S. L. and Devaney, S. P. (2006), 'Non-Normal Real Estate Return Distributions by Property Type in the UK', Journal of Property Research, 23 (2): 109-133. 
Table 1: Number of assets and number of sales in the dataset

\begin{tabular}{|c|c|c|c|c|c|c|c|}
\hline & \multirow{2}{*}{$\begin{array}{l}\text { Properties } \\
\text { in dataset }\end{array}$} & \multicolumn{3}{|c|}{ Number of properties after filtering } & \multirow[b]{2}{*}{ Retail } & \multirow[b]{2}{*}{ Office } & \multirow[b]{2}{*}{ Industrial } \\
\hline & & Total & $\%$ & Sales & & & \\
\hline Q1 2002 & 9,313 & 7,311 & $79 \%$ & 185 & 124 & 43 & 18 \\
\hline Q2 2002 & 9,442 & 7,313 & $77 \%$ & 358 & 223 & 79 & 56 \\
\hline Q3 2002 & 9,315 & 7,035 & $76 \%$ & 249 & 149 & 64 & 36 \\
\hline Q4 2002 & 9,283 & 6,896 & $74 \%$ & 275 & 163 & 78 & 34 \\
\hline Q1 2003 & 9,119 & 6,673 & $73 \%$ & 183 & 102 & 43 & 38 \\
\hline Q2 2003 & 9,018 & 6,777 & $75 \%$ & 250 & 112 & 55 & 83 \\
\hline Q3 2003 & 9,030 & 6,856 & $76 \%$ & 375 & 189 & 98 & 88 \\
\hline Q4 2003 & 8,821 & 6,655 & $75 \%$ & 212 & 91 & 76 & 45 \\
\hline Q1 2004 & 8,688 & 6,655 & $77 \%$ & 149 & 70 & 61 & 18 \\
\hline Q2 2004 & 8,798 & 6,615 & $75 \%$ & 193 & 75 & 66 & 52 \\
\hline Q3 2004 & 9,020 & 6,538 & $72 \%$ & 169 & 78 & 53 & 38 \\
\hline Q4 2004 & 9,276 & 6,582 & $71 \%$ & 185 & 69 & 70 & 46 \\
\hline Q1 2005 & 9,382 & 6,396 & $68 \%$ & 181 & 78 & 67 & 36 \\
\hline Q2 2005 & 9,411 & 6,472 & $69 \%$ & 131 & 63 & 35 & 33 \\
\hline Q3 2005 & 9,620 & 6,679 & $69 \%$ & 184 & 85 & 50 & 49 \\
\hline Q4 2005 & 9,944 & 6,796 & $68 \%$ & 251 & 113 & 69 & 69 \\
\hline Q1 2006 & 9,947 & 7,055 & $71 \%$ & 163 & 69 & 57 & 37 \\
\hline Q2 2006 & 9,990 & 7,143 & $72 \%$ & 132 & 56 & 47 & 29 \\
\hline Q3 2006 & 10,204 & 7,209 & $71 \%$ & 172 & 87 & 58 & 27 \\
\hline Q4 2006 & 10,336 & 7,348 & $71 \%$ & 242 & 115 & 69 & 58 \\
\hline Q1 2007 & 10,487 & 7,177 & $68 \%$ & 132 & 53 & 40 & 39 \\
\hline Q2 2007 & 10,456 & 7,309 & $70 \%$ & 109 & 52 & 23 & 34 \\
\hline Q3 2007 & 10,394 & 7,327 & $70 \%$ & 154 & 58 & 56 & 40 \\
\hline Q4 2007 & 10,307 & 7,204 & $70 \%$ & 151 & 73 & 44 & 34 \\
\hline Q1 2008 & 10,133 & 7,389 & $73 \%$ & 328 & 147 & 106 & 75 \\
\hline Q2 2008 & 9,700 & 7,369 & $76 \%$ & 241 & 107 & 72 & 62 \\
\hline Q3 2008 & 9,494 & 7,127 & $75 \%$ & 244 & 108 & 58 & 78 \\
\hline Q4 2008 & 9,133 & 7,189 & $79 \%$ & 148 & 71 & 32 & 45 \\
\hline Q1 2009 & 8,780 & 6,966 & $79 \%$ & 137 & 51 & 47 & 39 \\
\hline Q2 2009 & 8,644 & 6,851 & $79 \%$ & 217 & 92 & 60 & 65 \\
\hline Q3 2009 & 8,427 & 6,639 & $79 \%$ & 135 & 43 & 64 & 28 \\
\hline Q4 2009 & 8,540 & 6,704 & $79 \%$ & 192 & 81 & 47 & 64 \\
\hline Q1 2010 & 8,788 & 6,494 & $74 \%$ & 91 & 38 & 26 & 27 \\
\hline Q2 2010 & 8,877 & 6,303 & $71 \%$ & 142 & 58 & 53 & 31 \\
\hline
\end{tabular}


Table 2: Variables used in the regression models

\begin{tabular}{|c|c|}
\hline Variable name & Description of variable \\
\hline ANNTR & Total return achieved over last four quarters \\
\hline EYLD & $\begin{array}{l}\text { Equivalent yield in most recent quarter (yield assumes reversion to current } \\
\text { rental values) }\end{array}$ \\
\hline FUND1 & $\begin{array}{l}\text { Dummy equal to } 1 \text { if owned by a life insurance fund, } 0 \text { otherwise (omitted } \\
\text { category) }\end{array}$ \\
\hline FUND2 & Dummy equal to 1 if owned by a pension fund, 0 otherwise \\
\hline FUND3 & Dummy equal to 1 if owned by a property company, 0 otherwise \\
\hline FUND4 & Dummy equal to 1 if owned by a unitised fund, 0 otherwise \\
\hline FUND5 & Dummy equal to 1 if owned by another type of investor \\
\hline HOLDING & Holding period: measured precisely, but expressed in years \\
\hline INVMILLS & Inverse mills ratios produced by stage 1 probit model \\
\hline$L N C V$ & Log of the asset valuation made two quarters before sale \\
\hline LN PRICE & Log of the gross sale price (before fees) \\
\hline SALE & Dummy variable equal to 1 if asset sold in period, 0 otherwise \\
\hline SEG1 & $\begin{array}{l}\text { Dummy equal to } 1 \text { if property is a standard retail premises, } 0 \text { otherwise } \\
\text { (omitted category) }\end{array}$ \\
\hline SEG2 & Dummy equal to 1 if property is a shopping centre, 0 otherwise \\
\hline SEG3 & Dummy equal to 1 if property is a retail warehouse, 0 otherwise \\
\hline SEG4 & Dummy equal to 1 if property is a London office, 0 otherwise \\
\hline SEG5 & Dummy equal to 1 if property is an office outside London, 0 otherwise \\
\hline SEG6 & Dummy equal to 1 if property is an industrial property, 0 otherwise \\
\hline \multicolumn{2}{|c|}{ Models estimated } \\
\hline \multicolumn{2}{|l|}{ OLS: } \\
\hline \multicolumn{2}{|c|}{ 1) $L N P R I C E=\beta_{0}+\beta_{1} L N C V+\beta_{2} S E G 2+\beta_{3} S E G 3+\beta_{4} S E G 4+\beta_{5} S E G 5+\beta_{6} S E G 6$} \\
\hline \multicolumn{2}{|c|}{ Heckman procedure: } \\
\hline 1) & $\begin{array}{l}\nu_{1} L N C V+\gamma_{1} S E G 2+\gamma_{2} S E G 3+\gamma_{3} S E G 4+\gamma_{4} \text { SEG5 }+\gamma_{5} S E G 6+\gamma_{6} \text { FUND2 }+\gamma_{7} \text { FUND3 } \\
\gamma_{9} \text { FUND5 }+\gamma_{10} \text { ANNTR }+\gamma_{11} \text { EYLD }+\gamma_{12} \text { HOLDING }\end{array}$ \\
\hline 2) $L N P R I C E=$ & $+\beta_{1} L N C V+\beta_{2} S E G 2+\beta_{3} S E G 3+\beta_{4} S E G 4+\beta_{5} S E G 5+\beta_{6} S E G 6+\sigma I N V M I L L S$ \\
\hline
\end{tabular}


Table 3: Price model coefficients - OLS procedure

\begin{tabular}{|c|c|c|c|c|c|c|c|}
\hline & $\beta_{0}$ & LN CV & SEG2 & SEG3 & SEG4 & SEG5 & SEG6 \\
\hline Q1 2002 & $0.26^{* * *}$ & $0.98^{* * *}$ & $0.08^{* *}$ & $0.04 *$ & $0.05 * *$ & $0.04 * *$ & $0.05^{* *}$ \\
\hline Q2 2002 & $0.19^{* *}$ & $0.99^{* * *}$ & -0.03 & 0.02 & 0.00 & -0.02 & -0.02 \\
\hline Q3 2002 & 0.10 & $1.00 * * *$ & $0.07^{*}$ & 0.03 & $0.08^{* * *}$ & 0.00 & -0.02 \\
\hline Q4 2002 & $0.27^{* *}$ & $0.99 * * *$ & $0.08^{* *}$ & $0.09 * * *$ & 0.03 & 0.03 & 0.03 \\
\hline Q1 2003 & 0.11 & $1.00 * * *$ & -0.03 & 0.04 & 0.04 & -0.01 & 0.03 \\
\hline Q2 2003 & $0.23 * * *$ & $0.99^{* * *}$ & $-0.13^{* * *}$ & 0.04 & -0.01 & -0.02 & $-0.03 * *$ \\
\hline Q3 2003 & $0.16^{* *}$ & $0.99 * * *$ & -0.05 & 0.00 & $-0.03^{*}$ & $-0.03 * *$ & $-0.03^{* *}$ \\
\hline Q4 2003 & $0.52 * * *$ & $0.97 * * *$ & $0.10 *$ & $0.07^{* *}$ & $0.07^{* * *}$ & 0.01 & $0.04 * *$ \\
\hline Q1 2004 & $0.32 * *$ & $0.99 * * *$ & 0.07 & 0.01 & 0.00 & $-0.05 * *$ & -0.01 \\
\hline Q2 2004 & $0.71^{* * *}$ & $0.96^{* * *}$ & 0.10 & $0.06 *$ & $0.06^{*}$ & 0.02 & -0.02 \\
\hline Q3 2004 & $0.32 * * *$ & $0.99^{* * *}$ & 0.02 & -0.01 & 0.02 & -0.03 & 0.00 \\
\hline Q4 2004 & $0.44^{* * *}$ & $0.98 * * *$ & 0.02 & 0.03 & $0.05^{* *}$ & -0.02 & $-0.05 * * *$ \\
\hline Q1 2005 & $0.48^{* * *}$ & $0.97^{* * *}$ & 0.04 & $0.05 *$ & 0.02 & $0.04 *$ & -0.02 \\
\hline Q2 2005 & 0.08 & $1.00 * * *$ & -0.08 & $-0.08 * *$ & -0.04 & $-0.07^{* *}$ & $-0.07 * * *$ \\
\hline Q3 2005 & $0.22 * *$ & $0.99 * * *$ & 0.08 & 0.05 & 0.00 & 0.01 & 0.02 \\
\hline Q4 2005 & $0.24^{* *}$ & $0.99 * * *$ & 0.05 & $0.11^{* * *}$ & $0.19^{* * *}$ & 0.01 & 0.01 \\
\hline Q1 2006 & 0.13 & $1.00^{* * *}$ & 0.06 & 0.05 & $0.09^{* * *}$ & 0.03 & 0.01 \\
\hline Q2 2006 & -0.04 & $1.01 * * *$ & $0.14^{* *}$ & -0.05 & 0.03 & -0.02 & -0.04 \\
\hline Q3 2006 & 0.18 & $0.99 * * *$ & 0.06 & 0.00 & 0.04 & 0.02 & -0.01 \\
\hline Q4 2006 & $0.38 * * *$ & $0.98 * * *$ & 0.07 & $0.06^{* *}$ & $0.09 * * *$ & 0.00 & $0.03 *$ \\
\hline Q1 2007 & 0.16 & $0.99 * * *$ & 0.02 & 0.02 & 0.03 & 0.00 & -0.02 \\
\hline Q2 2007 & 0.06 & $1.00^{* * *}$ & -0.03 & -0.03 & $0.08^{*}$ & $0.07^{*}$ & -0.05 \\
\hline Q3 2007 & 0.10 & $0.99 * * *$ & 0.00 & 0.03 & $0.21 * * *$ & 0.03 & $0.06^{* *}$ \\
\hline Q4 2007 & 0.31 & $0.98 * * *$ & 0.10 & 0.03 & 0.05 & $0.08^{* *}$ & 0.01 \\
\hline Q1 2008 & $0.24 * *$ & $0.98 * * *$ & $0.08^{* *}$ & 0.00 & -0.03 & 0.00 & 0.00 \\
\hline Q2 2008 & 0.07 & $0.99 * * *$ & 0.03 & -0.03 & 0.03 & 0.00 & 0.01 \\
\hline Q3 2008 & -0.17 & $1.00 * * *$ & 0.04 & 0.03 & 0.06 & -0.01 & $0.06^{* *}$ \\
\hline Q4 2008 & $-0.43^{* *}$ & $1.02 * * *$ & $-0.19^{*}$ & $-0.14^{* * *}$ & $-0.08^{*}$ & 0.00 & 0.01 \\
\hline Q1 2009 & 0.16 & $0.98 * * *$ & $0.74 * * *$ & $-0.13^{* * *}$ & 0.01 & 0.01 & -0.04 \\
\hline Q2 2009 & $0.34^{* *}$ & $0.97^{* * *}$ & $\mathrm{~N} / \mathrm{A}$ & -0.01 & 0.00 & 0.01 & $-0.05^{* *}$ \\
\hline Q3 2009 & 0.23 & $0.99 * * *$ & $-0.14 *$ & -0.05 & -0.05 & $-0.09 * * *$ & -0.04 \\
\hline Q4 2009 & 0.03 & $1.01^{* * *}$ & -0.10 & 0.03 & -0.01 & 0.00 & -0.04 \\
\hline Q1 2010 & 0.03 & $1.00^{* * *}$ & 0.02 & $0.22 * * *$ & 0.11 & -0.09 & -0.05 \\
\hline Q2 2010 & $0.35 *$ & $0.98^{* * *}$ & 0.00 & $0.08^{* *}$ & $0.14^{* * *}$ & 0.01 & -0.02 \\
\hline
\end{tabular}

$*, * *, * * *$ equal significance from zero at the $10 \%, 5 \%$ and $1 \%$ levels, respectively

$\mathrm{N} / \mathrm{A}$ denotes no sales with which to estimate segment dummy (see discussion in main text) 
Table 4: Price model coefficients - Heckman two-step procedure

\begin{tabular}{|c|c|c|c|c|c|c|c|c|}
\hline & $\beta_{0}$ & LN CV & SEG2 & SEG3 & SEG4 & SEG5 & SEG6 & INVM \\
\hline Q1 2002 & $0.19 *$ & $0.98 * * *$ & $0.10^{* *}$ & $0.05^{* *}$ & 0.04 & 0.03 & 0.01 & 0.09 \\
\hline Q2 2002 & 0.12 & $1.00 * * *$ & -0.04 & 0.02 & -0.01 & -0.01 & 0.00 & -0.06 \\
\hline Q3 2002 & 0.13 & $0.98 * * *$ & $0.11^{* *}$ & 0.01 & $0.07^{* * *}$ & -0.01 & $-0.06 * *$ & $0.14^{* * *}$ \\
\hline Q4 2002 & $0.30^{* *}$ & $1.03^{* * *}$ & -0.05 & $0.13^{* * *}$ & 0.03 & 0.04 & $0.14^{* *}$ & $-0.30 *$ \\
\hline Q1 2003 & 0.05 & $1.03^{* * *}$ & -0.03 & 0.01 & 0.00 & 0.01 & $0.05^{* *}$ & $-0.17^{* * *}$ \\
\hline Q2 2003 & $0.24^{* * *}$ & $1.01 * * *$ & $-0.16^{* * *}$ & 0.04 & -0.01 & -0.01 & $-0.05 * *$ & -0.10 \\
\hline Q3 2003 & $0.16^{* *}$ & $0.99 * * *$ & -0.05 & 0.00 & $-0.04^{* *}$ & $-0.04 * * *$ & $-0.03^{* *}$ & 0.01 \\
\hline Q4 2003 & $0.60 * * *$ & $0.97^{* * *}$ & $0.10 *$ & $0.05^{* *}$ & $0.06^{* *}$ & 0.00 & $0.04^{* *}$ & $-0.05^{*}$ \\
\hline Q1 2004 & $0.37^{* *}$ & $0.98 * * *$ & 0.07 & 0.01 & -0.01 & $-0.05^{* *}$ & -0.01 & -0.02 \\
\hline Q2 2004 & $0.25 *$ & $0.97^{* * *}$ & 0.08 & $0.06 * *$ & $0.06 *$ & $0.05^{* *}$ & 0.01 & $0.12^{* * *}$ \\
\hline Q3 2004 & $0.26^{* *}$ & $0.98 * * *$ & 0.02 & -0.03 & 0.02 & $-0.04 *$ & -0.02 & $0.07^{* * *}$ \\
\hline Q4 2004 & 0.12 & $0.98 * * *$ & 0.00 & 0.03 & $0.06^{* *}$ & 0.00 & $-0.05^{* * *}$ & $0.09 * *$ \\
\hline Q1 2005 & $0.36 * * *$ & $0.97^{* * *}$ & 0.04 & 0.04 & 0.03 & $0.04 *$ & -0.03 & $0.05^{* *}$ \\
\hline Q2 2005 & $0.50 * *$ & $1.01 * * *$ & 0.03 & -0.05 & 0.01 & -0.04 & -0.03 & $-0.19 * *$ \\
\hline Q3 2005 & 0.18 & $0.99 * * *$ & 0.05 & 0.04 & -0.01 & 0.01 & 0.01 & 0.04 \\
\hline Q4 2005 & $0.21 *$ & $0.99 * * *$ & 0.05 & $0.11^{* * *}$ & $0.19^{* * *}$ & 0.01 & 0.01 & 0.03 \\
\hline Q1 2006 & 0.15 & $0.97^{* * *}$ & $0.10^{*}$ & 0.05 & $0.09 * * *$ & $0.05 *$ & 0.00 & $0.14 *$ \\
\hline Q2 2006 & -0.08 & $1.02 * * *$ & 0.12 & -0.05 & 0.02 & -0.03 & -0.04 & -0.03 \\
\hline Q3 2006 & 0.10 & $1.00 * * *$ & 0.05 & 0.00 & 0.04 & 0.02 & -0.02 & 0.03 \\
\hline Q4 2006 & $0.37^{* * *}$ & $0.98^{* * *}$ & 0.07 & $0.06^{* *}$ & $0.09 * * *$ & 0.00 & $0.03 *$ & 0.01 \\
\hline Q1 2007 & 0.23 & $0.99 * * *$ & 0.01 & 0.02 & 0.02 & -0.01 & -0.02 & -0.04 \\
\hline Q2 2007 & $-0.55^{*}$ & $0.99 * * *$ & $0.18^{* *}$ & -0.03 & 0.08 & 0.02 & -0.04 & $0.29^{* * *}$ \\
\hline Q3 2007 & 0.75 & $1.04^{* * *}$ & 0.08 & $0.35^{*}$ & $0.15 *$ & -0.01 & 0.11 & $-0.58^{* *}$ \\
\hline Q4 2007 & $0.48^{* *}$ & $0.99 * * *$ & 0.18 & 0.08 & 0.02 & $0.11^{* * *}$ & 0.05 & $-0.19 * *$ \\
\hline Q1 2008 & 0.27 & $0.94 * * *$ & $0.12 * *$ & -0.05 & 0.02 & 0.00 & $-0.06 * *$ & $0.31^{* * *}$ \\
\hline Q2 2008 & 0.15 & $0.97^{* * *}$ & 0.05 & -0.02 & $0.05 *$ & 0.00 & -0.01 & $0.13^{* * *}$ \\
\hline Q3 2008 & $-0.41^{* *}$ & $0.99 * * *$ & 0.08 & -0.01 & 0.05 & -0.06 & $0.06^{* *}$ & $0.21^{* * *}$ \\
\hline Q4 2008 & $-0.61 * *$ & $1.01 * * *$ & $-0.26 * *$ & $-0.20 * * *$ & $-0.13^{* *}$ & -0.05 & -0.03 & $0.13^{* *}$ \\
\hline Q1 2009 & -0.17 & $0.97^{* * *}$ & $0.64 * * *$ & $-0.22 * * *$ & -0.01 & -0.02 & $-0.08^{* *}$ & $0.20^{* * *}$ \\
\hline Q2 2009 & -0.08 & $0.97^{* * *}$ & $\mathrm{~N} / \mathrm{A}$ & -0.01 & 0.02 & -0.04 & $-0.06 * *$ & $0.23^{* * *}$ \\
\hline Q3 2009 & $0.87^{* * *}$ & $1.00 * * *$ & -0.16 & $-0.14 * *$ & $-0.17^{* * *}$ & $-0.22 * * *$ & -0.04 & $-0.30 * * *$ \\
\hline Q4 2009 & 0.17 & $1.01^{* * *}$ & -0.07 & 0.03 & -0.01 & 0.01 & -0.04 & -0.07 \\
\hline Q1 2010 & -0.72 & $1.01^{* * *}$ & 0.06 & $0.20 * * *$ & 0.10 & -0.10 & -0.03 & $0.23^{* * *}$ \\
\hline Q2 2010 & -0.07 & $0.98 * * *$ & 0.01 & $0.11 * * *$ & $0.18^{* * *}$ & 0.04 & -0.04 & $0.21^{* * *}$ \\
\hline
\end{tabular}

$*, * *, * * *$ equal significance from zero at the $10 \%, 5 \%$ and $1 \%$ levels, respectively

$\mathrm{N} / \mathrm{A}$ denotes no sales with which to estimate segment dummy (see discussion in main text) 
Table 5: Summary statistics for real estate indices

\begin{tabular}{|c|c|c|c|c|c|c|c|c|c|}
\hline & $\begin{array}{l}\text { Peak of } \\
\text { index }\end{array}$ & $\begin{array}{l}\text { Trough of } \\
\text { index }\end{array}$ & $\begin{array}{c}\text { Capital } \\
\text { growth to } \\
\text { peak }\end{array}$ & $\begin{array}{l}\text { Fall: peak to } \\
\text { trough }\end{array}$ & $\begin{array}{c}\text { Geometric } \\
\text { mean } \\
\text { growth }\end{array}$ & $\begin{array}{l}\text { Arithmetic } \\
\text { mean } \\
\text { growth }\end{array}$ & $\begin{array}{c}\text { Standard } \\
\text { deviation of } \\
\text { changes }\end{array}$ & $\begin{array}{c}\text { First order } \\
\text { autocorrelation } \\
\text { of changes }\end{array}$ & $\begin{array}{c}\text { Ratio of } \\
\text { standard } \\
\text { deviations }^{1}\end{array}$ \\
\hline \multicolumn{10}{|c|}{ Panel A: Appraisal based indices } \\
\hline All Property & Q2 2007 & Q2 2009 & 53.2 & -42.4 & 0.09 & 0.19 & 4.54 & 0.76 & \\
\hline Retail & Q2 2007 & Q2 2009 & 68.0 & -43.6 & 0.37 & 0.49 & 4.89 & 0.75 & \\
\hline Office & Q2 2007 & Q2 2009 & 37.8 & -42.7 & -0.30 & -0.19 & 4.59 & 0.78 & \\
\hline Industrial & Q2 2007 & Q2 2009 & 43.8 & -40.4 & -0.13 & -0.05 & 4.08 & 0.77 & \\
\hline \multicolumn{10}{|c|}{ Panel B: OLS transaction based indices } \\
\hline All Property & Q3 2007 & Q2 2009 & 61.1 & -43.0 & 0.15 & 0.35 & 6.21 & 0.02 & 1.37 \\
\hline Retail & Q2 2006 & Q2 2009 & 80.9 & -43.5 & 0.51 & 0.89 & 8.58 & -0.30 & 1.76 \\
\hline Office & Q3 2007 & Q2 2009 & 49.7 & -43.7 & -0.14 & 0.07 & 6.64 & 0.12 & 1.44 \\
\hline Industrial & Q3 2007 & Q2 2009 & 50.8 & -44.0 & -0.12 & 0.06 & 5.98 & 0.20 & 1.47 \\
\hline \multicolumn{10}{|c|}{ Panel C: Selection corrected transaction indices } \\
\hline All Property & Q2 2007 & Q1 2009 & 73.2 & -50.7 & 0.06 & 0.27 & 6.47 & 0.39 & 1.42 \\
\hline Retail & Q2 2007 & Q1 2009 & 107.2 & -57.7 & 0.20 & 0.50 & 7.78 & 0.33 & 1.59 \\
\hline Office & Q3 2007 & Q3 2009 & 62.2 & -46.8 & 0.40 & 0.68 & 7.69 & 0.26 & 1.67 \\
\hline Industrial & Q2 2007 & Q4 2009 & 35.6 & -47.7 & -0.73 & -0.56 & 5.72 & 0.28 & 1.40 \\
\hline \multicolumn{10}{|c|}{ Panel D: Real estate equities index } \\
\hline FTRE/FTREIT & Q4 2006 & Q1 2009 & 162.3 & -76.3 & -0.60 & 0.51 & 14.6 & 0.24 & 3.21 \\
\hline
\end{tabular}

${ }^{1}=$ ratio is calculated using the equivalent appraisal based series. For FTRE/FTREIT, the comparison is with the IPD All Property appraisal based index. 
Table 6: Distribution statistics and test for normality

\begin{tabular}{|c|c|c|c|c|c|c|}
\hline & $\begin{array}{l}\text { Maximum } \\
\text { growth }\end{array}$ & $\begin{array}{l}\text { Minimum } \\
\text { growth }\end{array}$ & Skewness & $\begin{array}{c}\text { Excess } \\
\text { kurtosis }^{1}\end{array}$ & $\begin{array}{c}\text { JB test } \\
\text { statistic }\end{array}$ & P-value \\
\hline \multicolumn{7}{|c|}{ Panel A: Appraisal based indices } \\
\hline All Property & 8.1 & -14.3 & -1.46 & 2.46 & 20.0 & 0.00 \\
\hline Retail & 9.7 & -15.0 & -1.40 & 2.44 & 19.0 & 0.00 \\
\hline Office & 6.4 & -14.0 & -1.21 & 1.49 & 11.2 & 0.00 \\
\hline Industrial & 6.7 & -13.6 & -1.56 & 2.80 & 24.3 & 0.00 \\
\hline \multicolumn{7}{|c|}{ Panel B: OLS transaction based indices } \\
\hline All Property & 10.3 & -18.2 & -1.29 & 2.00 & 14.7 & 0.00 \\
\hline Retail & 23.6 & -27.8 & -0.83 & 4.25 & 28.6 & 0.00 \\
\hline Office & 12.7 & -14.6 & -0.16 & -0.11 & 0.2 & 0.92 \\
\hline Industrial & 9.1 & -14.9 & -0.61 & -0.03 & 2.1 & 0.36 \\
\hline \multicolumn{7}{|c|}{ Panel C: Selection corrected transaction indices } \\
\hline All Property & 13.0 & -13.2 & -0.37 & 0.00 & 0.7 & 0.69 \\
\hline Retail & 15.5 & -17.2 & -0.61 & 0.09 & 2.1 & 0.35 \\
\hline Office & 20.2 & -14.3 & 0.43 & 0.21 & 1.1 & 0.59 \\
\hline Industrial & 8.4 & -14.8 & -0.82 & 0.46 & 4.0 & 0.13 \\
\hline \multicolumn{7}{|c|}{ Panel D: Real estate equities index } \\
\hline FTRE/FTREIT & 27.9 & -34.2 & -0.55 & 0.05 & 1.7 & 0.43 \\
\hline
\end{tabular}

${ }^{1}=$ adjusted so that normal distribution would have a kurtosis of zero. 
Figure 1: Sales per quarter and market performance

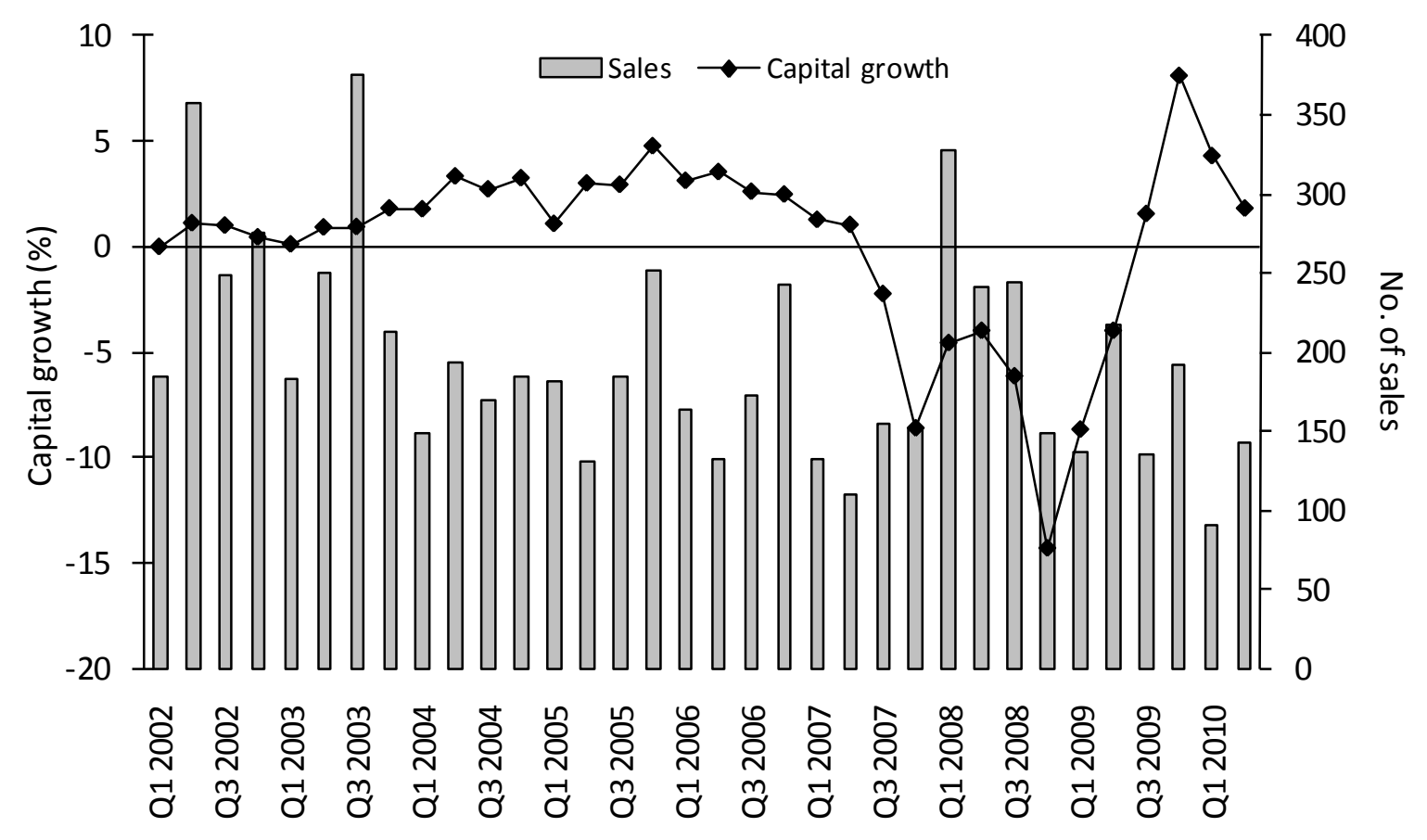


Figure 2: Comparison of transaction and appraisal based capital growth indices

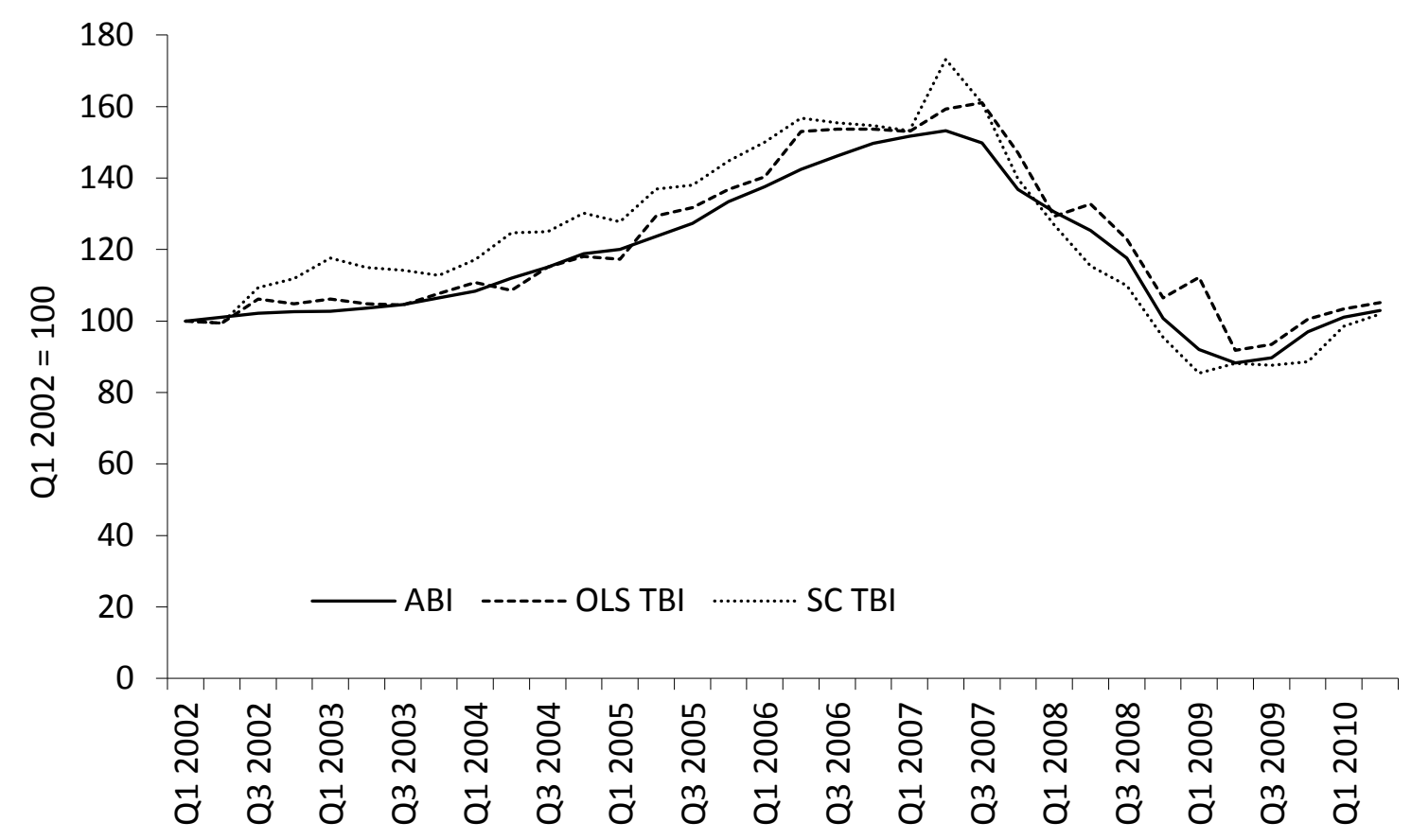


Figure 3: Changes in the transaction and appraisal based capital growth indices

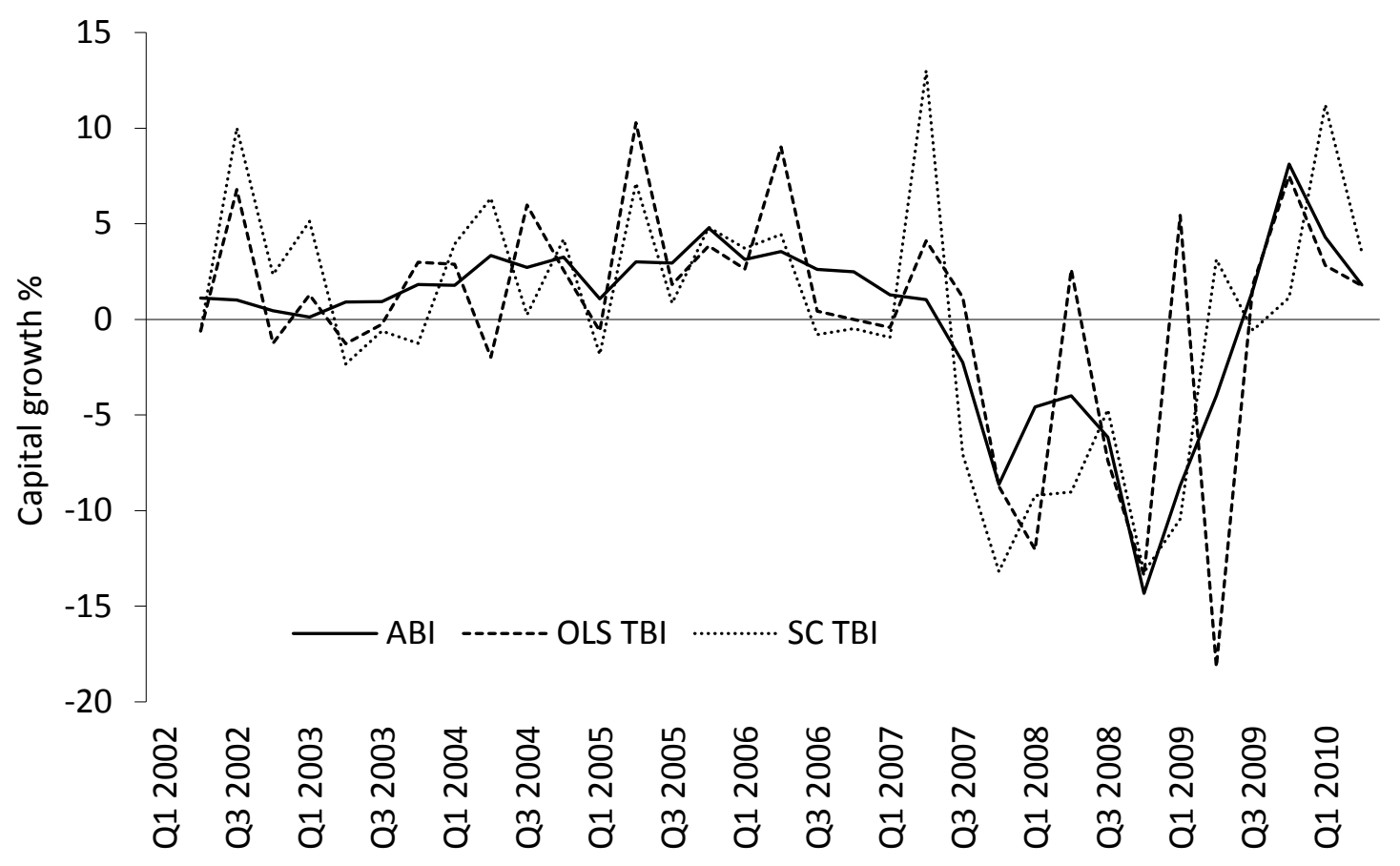

